\title{
Penile Cancer in Cali, Colombia: 10 Years of Casuistry in a Tertiary Referral Center of a Middle-Income Country
}

\author{
Lina M. Rengifo, ${ }^{1}$ Maria del M. Herrera, ${ }^{1}$ Angie L. Rincon-Jimenez, ${ }^{1}$ Alberto J. Bermudez-Pupo, ${ }^{2}$ Francisco J. Bonilla-Escobar. ${ }^{3}$
}

\begin{abstract}
Background: Background: Penile cancer is a rare disease in Colombia; in Cali, it represents $0.7 \%$ of all cancers. Penile cancer has been associated with old age, bad hygiene, smoking and lack of circumcision. This study aimed to describe the sociodemographic and clinical characteristics of patients with penile cancer who consulted to a tertiary referral hospital. Methods: A case series of all penile cancer cases at a reference institution in Cali during 2001-2010. Socioeconomic, demographic and clinical features of patients were described, and bivariate analyses were carried out. Results: There were 46 penile cancer cases. The average age was $60 \pm 16.9$ years. The main reason for consultation was an exophytic mass on the penis (75.0\%). The most common location was the glans $(69.6 \%)$, and the more frequent histology type was the squamous cell carcinoma (95.7\%). With regard to risk factors, $65.5 \%$ of the patients had history of smoking and $90.9 \%$ did not have circumcision. Patients who underwent radical amputation had higher rates of positive nodes $(55 \%$ vs. $13.5 \%, p=0.015)$ and ulcerative lesions ( $77.8 \%$ vs. $29.7 \%, p=0.018$ ) than those who did not have the procedure done. Recurrence was associated with the presence of lymphadenopathy $(p=0.02)$ and history of circumcision $(p=0.015)$. Conclusion: Most of the patients with penile cancer found in this study had old age, history of tobacco use and lack of circumcision. Patients who presented with lymph node metastasis had to undergo more radical procedures and suffered a greater rate of recurrence compared with those without lymph node involvement. Robust studies to determine the risk factors among low-income populations are required.
\end{abstract}

Keywords: Penile Neoplasms; Circumcision, Male; Smoking; Developing Countries (Source: MeSH-NLM).

\section{Introduction}

Penile cancer is a rare malignancy worldwide, accounting for less than $0.5 \%$ of all cancers diagnosed in men.' It is less common in high-income countries like Europe and the United States, where it accounts for $0.4 \%-0.6 \%$ of all malignancies, with an age-adjusted incidence of 0.3 to 1 in 100,000 men. $^{2,3}$ In lowand middle-income countries such as African and South American countries, it represents about $10 \%$ of all malignancies, with an annual age-adjusted rate between 2.3 to 8.3 per 100,000 men and Brazil being the country with the highest incidence in the world. 4.5

Penile cancer usually affects men over 50 years, but up to $19 \%$ of the cases occur in men under 40 years and $7 \%$ in men younger than 30 years. ${ }^{5}$ In $95 \%$ of the cases, penile cancer originates from the squamous cell tissue located in the inner layer of the glans $(80 \%)$ or foreskin $(15 \%)^{6} .^{6-11}$ Risk factors that have been associated with penile cancer include poor hygiene, phimosis, dermatitis, traumatic injury of the penis, infection with the Human Papilloma Virus (HPV) and smoking. ${ }^{12-14}$ Early circumcision acts as a protective factor since it prevents phimosis. ${ }^{15,16}$

In 2003, Ramírez and Bermúdez-Pupo published a study describing the population with penile cancer in a referral hospital in Cali, Colombia between 1990 and 2000, in which they found a total of 59 cases of penile cancer, with a mean age of 52 years, $87 \%$ of patients had a history of smoking, $10 \%$ had HPV infection and $80 \%$ had no circumcision. ${ }^{17}$ According to later data from the Population-based Cancer Registry of Cali (RPCC), 63 cases of penile carcinoma were reported during the 2004-2008 period. This type of carcinoma accounted for $0.7 \%$ of all diagnosed cancers, and the age-adjusted incidence was 1.3 per 100,000 person-year (Available from: http://rpcc.univalle.edu. co/in/, updated 2008; cited 2013 Jun 1).

Although penile cancer is a rare disease in Cali, it can yield terrible consequences on the social and emotional life of patients living with it. The cancer usually afflicts men of low socioeconomic status, and the diagnosis is frequently made in advanced stages of the disease when treatment options are drastic. It is therefore necessary to know the changes in these sociodemographic factors and the clinical features associated with the onset and the prognosis of penile cancer in this population in order to identify research areas and potential prevention strategies. The objective of this study is to describe the sociodemographic and clinical characteristics of patients with penile cancer who consulted to a tertiary referral hospital in Cali, Colombia during 2001-2010.

\section{Methods}

This is a case series study of patients admitted to a public reference institution in Cali with histopathological diagnosis of penile cancer made between January of 2001 and December of 2010. The institution where the study was carried out admits

${ }^{1}$ Fifth year Medical Student, Faculty of Health, Universidad del Valle, Cali, Colombia.

${ }^{2} \mathrm{MD}$, Urologist, Professor, Urology Department, Universidad del Valle, Hospital Universitario del Valle "Evaristo Garcia" ESE, Cali, Colombia.

${ }^{3} \mathrm{MD}, \mathrm{MSc}(\mathrm{c})$, Editor in Chief IJMS. Research Associate, Cisalva Institute, Universidad del Valle, Cali, Colombia.

\section{Correspondence:}

Lina M. Rengifo.

Address: Calle 4B\#36-00, School of Medicine, Faculty of Health, Universidad del Valle, Building 100, Cali, Colombia.

Email: linamarce90@hotmail.com 
patients from the entire southwestern region of Colombia and is one of the most important public institutions in the country. The clinical records of patients registered with the diagnosis of penile cancer were reviewed. For cancer staging, the international TNM classification was used.

The data collection consisted of three parts: sociodemographic characteristics, patient's clinical features and the tumor's characteristics. The database was created in Microsoft Access $2010 ®$ program, and an exploratory analysis was performed to look for extreme and missing values, and typing errors.

Some variables were recategorized. Residency was further divided into three groups: Cali, other municipalities of Valle del Cauca and other departments of Colombia. Marital status was divided into two groups: with partner and without partner; occupational status into five groups: unemployed, farmer, various trades, street seller and others; and associated symptoms into six groups: none, urinary, pain, hydrocele, secretion and constitutional.

Univariate and bivariate analyses were performed. Description of the variables was presented using measures of central tendency and dispersion (average and standard deviation [SD]) for quantitative variables and frequencies and percentages for categorical variables. Then, application of hypothesis testing was carried out according to the nature of the variables. For quantitative variables, Student $t$ test was used given the number of groups, the normal distribution and equal variances of the variables analyzed. For categorical variables, Fisher's exact test was used. All analyses were performed with a significance level of 0.05 with Stata13 ${ }^{\circledR}$ (StataCorp, TX, USA).

This study is adherent to the STrengthening the Reporting of OBservational studies in Epidemiology (STROBE) Statement. ${ }^{18}$ Additionally, it has the approval of the Institutional Review Board of Universidad del Valle.

\section{Results}

\section{Description of the Study Population}

The initial database consisted of 71 clinical histories, of which 25 had to be excluded: 10 had a diagnosis other than penile cancer, 4 were not found in the files, 3 had no confirmed diagnosis, 1 due to illegible handwriting and 7 with a diagnosis date before January 2001. After the exclusions, a total of 46 medical records were analyzed.

The age range was between 29 and 103 years, with a mean age of $60 \pm 16.9$ years. Two patients $(4.3 \%)$ were younger than 40 years, and eight patients $(17.4 \%)$ died during the study period.

Most of the patients $(54.3 \%)$ had their educational attainment recorded in their medical record. Of these, $60.0 \%$ completed basic primary education and one patient $(4.0 \%)$ had a postgraduate degree. For insurance status, $87.0 \%$ of the patients were under the state-subsidized regime, $6.5 \%$ did not have any insurance and $4.4 \%$ were in the contributory regime.

Most of the patients (78.3\%) were from Cali or other municipalities of Valle del Cauca, and the remaining $21.7 \%$ were from other departments in the southwest region of Colombia.
In terms of occupation, $37.0 \%$ of the patients were farmers and $19.6 \%$ were unemployed at the time of the study. Within the group of patients who had an occupation, 59\% did their work outdoors in the fields of agriculture, street vending, construction, etc. Finally, for marital status, $54.5 \%$ of the patients had a stable partner and $45.5 \%$ had no partner.

\section{Clinical Features}

The most frequent cause of consultation among patients studied was the appearance of a mass on the patient's penis $(60.9 \%)$, followed by the appearance of an ulcer $(39.1 \%)$. More than two thirds (78.3\%) of the patients did not report the presence of adenopathy during the first visit, and $6.5 \%$ consulted due to phimosis.

For the physical examination item, $75.0 \%$ of the patients had an exophytic mass and $25.0 \%$ an ulcer. For tumor localization, $69.6 \%$ had the glans involved, $41.3 \%$ the penile shaft, $39 \%$ the foreskin and $21.7 \%$ the coronal sulcus. Involvement of more than one region of the penis was reported in $27.5 \%$ of the patients.

Almost half of the patients $(45.7 \%)$ reported consultation to a general physician or specialist before the diagnosis of penile cancer was made, and $78.6 \%$ reported an evolution time between 2 and 24 months. More than half of the patients ( $58.7 \%$ ) did not have any additional symptom associated with the cause of consultation. Among those who consulted with additional symptom(s), $17.4 \%$ reported urinary symptoms and $13.0 \%$ bloody or purulent discharge from the penis.

History of smoking was found in $65.5 \%$ of the patients, and $90.9 \%$ of the patients had no history of circumcision at the time of their first consultation. The recurrence rate among patients who had had circumcision (2 patients) was $100 \%$, in contrast to the uncircumcised group of patients (27 patients) whose recurrence rate was $8 \%(p=0.015)$.

History of sexually transmitted diseases (STDs) was denied by $86.7 \%$ of the patients; $6.5 \%$ of the patients reported a history of syphilis, $4.4 \%$ gonorrhea, and $2.2 \%$ had human immunodeficiency virus (HIV) infection. The patients with a history of STDS were younger compared with those without such history, with a mean age of $47.2 \pm 5.38$ years and $61.8 \pm 17.26$ years, respectively $(p=0.047)$. Patients with a history of STD presented with an ulcerative lesion more frequently than patients with no history of STD ( $66.7 \%$ vs. $17.6 \%$, respectively; $p=0.038$ ) (Table 1 ).

\section{Tumor Features}

Half of the cases had an advanced T2 or T3 clinical stage. In $37 \%$ of the cases, it was not possible to determine the node involvement (NX). Involvement of multiple superficial inguinal nodes ( $\mathrm{N}_{2}$ ) was found in $21.7 \%$ of the patients; $19.6 \%$ were classified as $\mathrm{N}_{1}$ and $15.2 \%$ had no evidence of lymph node metastasis (No). Evidence of metastasis to distant organs was absent (Mo) or could not be determined (MX) in $84.8 \%$ of the patients. Patients with nodal involvement $\left(\mathrm{N}_{1}-\mathrm{N}_{3}\right)$ presented metastasis more frequently than those with no evidence of nodal involvement (No, NX): $27 \%$ vs. $4 \%$, respectively $(\mathrm{p}=0.042)$.

Regarding the tumor grade, $65.2 \%$ of the cases were well diffe- 
Table 1. Relationship between Past Medical History and Sociodemographic and Clinical Characteristics of Patients with Penile Cancer Diagnosis in a Tertiary Referral Hospital in Cali, Colombia, 2001-2010.

\begin{tabular}{|c|c|c|c|c|c|c|c|c|c|c|c|c|}
\hline \multirow{2}{*}{ Characteristic } & \multicolumn{4}{|c|}{ Smoking } & \multicolumn{4}{|c|}{ History of STDs } & \multicolumn{4}{|c|}{ History of Circumcision } \\
\hline & No & Yes & Total & $p^{*}$ & No & Yes & Total & $p^{*}$ & No & Yes & Total & $p^{*}$ \\
\hline \multicolumn{13}{|l|}{ Education } \\
\hline None & 0 & 1 & 1 & 0.88 & 3 & 0 & 3 & 0.34 & 2 & 0 & 2 & 0.63 \\
\hline Basic primary school & 5 & 7 & 12 & & 11 & 4 & 15 & & 11 & 1 & 12 & \\
\hline High school & 0 & 2 & 2 & & 5 & 1 & 6 & & 3 & 1 & 4 & \\
\hline Postgraduate degree & 0 & 1 & 1 & & 1 & 0 & 1 & & 1 & 0 & 1 & \\
\hline \multicolumn{13}{|l|}{ Marital status } \\
\hline Stable partner & 6 & 9 & 15 & 1.00 & 20 & 4 & 24 & 0.43 & 14 & 2 & 16 & 0.50 \\
\hline No partner & 4 & 8 & 12 & & 18 & 2 & 20 & & 15 & 1 & 16 & \\
\hline \multicolumn{13}{|l|}{ Form of presentation } \\
\hline Exophytic mass & 9 & 13 & 22 & 0.26 & 28 & 2 & 30 & 0.04 & 21 & 2 & 23 & 0.11 \\
\hline Ulcer & 0 & 4 & 4 & & 6 & 4 & 10 & & 7 & 1 & 8 & \\
\hline \multicolumn{13}{|l|}{ Tumor localization } \\
\hline Foreskin & 6 & 7 & 13 & 0.27 & 15 & 3 & 18 & 0.44 & 13 & 3 & 16 & 0.10 \\
\hline Glans & 8 & 14 & 22 & 0.54 & 29 & 3 & 32 & 0.25 & 23 & 3 & 26 & 0.48 \\
\hline Coronal sulcus & 8 & 2 & 10 & 0.01 & 9 & 1 & 10 & 0.61 & 7 & 1 & 8 & 0.58 \\
\hline Penile shaft & 3 & 9 & 12 & 0.30 & 16 & 3 & 19 & 0.48 & 11 & 0 & 11 & 0.28 \\
\hline \multicolumn{13}{|l|}{ Histologic Grade } \\
\hline High grade & 0 & 1 & 1 & 0.83 & 1 & 0 & 1 & 0.83 & 19 & 3 & 22 & 0.66 \\
\hline Well differentiated & 7 & 12 & 19 & & 26 & 4 & 30 & & 1 & 0 & 1 & \\
\hline Undifferentiated & 0 & 1 & 1 & & 2 & 0 & 2 & & 1 & 0 & 1 & \\
\hline Moderately differentiated & 2 & 5 & 7 & & 9 & 21 & 11 & & 8 & 0 & 8 & \\
\hline \multicolumn{13}{|l|}{ Treatment } \\
\hline Partial amputation & 6 & 12 & 4 & 0.57 & 25 & 3 & 28 & 0.44 & 20 & 2 & 22 & 0.72 \\
\hline Radical amputation & 1 & 3 & 18 & 0.60 & 7 & 2 & 9 & 0.33 & 5 & 1 & 6 & 0.46 \\
\hline
\end{tabular}

* Fisher exact test. STDs: sexually transmitted diseases.

rentiated and $23.9 \%$ were moderately differentiated. The predominant histological type was squamous cell carcinoma (95.7\%); melanoma was found in one patient (2.2\%) and leiomyosarcoma in another patient.

As for the treatment, $60.9 \%$ of the patients underwent partial amputation and $20.0 \%$ radical amputation. Of these patients, $65.2 \%$ also underwent lymph node dissection. Therapeutic alternatives received included chemotherapy $(6.5 \%)$, radiotherapy $(4.5 \%)$ and circumcision (10.9\%).

None of the 39 patients without evidence of distant metastases and classified as Mo/MX underwent pharmacological management, while $28.6 \%$ of the patients classified as $M_{1}$ received such management $(p=0.002)$ (Table 2$)$. The patients who underwent radical amputation had positive nodes and ulcerative lesions at higher rates than those who did not undergo this procedure (positive nodes: $55.0 \%$ and $13.5 \%$, respectively, $p=0.015$; ulcerative lesions: $77.8 \%$ and $29.7 \%$, respectively, $p=0.018$ ).

Recurrence was found in $5.8 \%$ of the patients; of these, $33.2 \%$ involved the stump area. Recurrence was associated with the presence of lymphadenopathy $(p=0.02)$ and history of circumcision $(p=0.015)$

\section{Discussion}

The present study allowed for a description of the sociodemo graphic and clinical characteristics of patients diagnosed with penile cancer who consulted to a tertiary-level referral institution in Cali over a period of 10 years (2001-2010).

\section{Sociodemographic Characteristics}

It was found that the age groups most commonly affected by this type of cancer were men between 43 and 77 years, similar to results of previous studies that reported a higher incidence in men above 50 years old.5,19 Chaux et al. reported that up to $91 \%$ of patients with penile cancer have a low educational level. ${ }^{19}$ This finding is supported by the present study where most patients had completed only basic primary education.

Subscription to a subsidized health insurance regime in Colombia indicates a low-income status. Eight-seven percent of the studied patients belonged to this regime, which is consistent with the study by Hernandez et al. which found a $43 \%$ greater risk of penile cancer in countries where more than $20 \%$ of the population lives in poverty compared to countries with less than $10 \%$ living in poverty. ${ }^{20}$ However, it is important to note that the institution where the study was carried out serves primarily the poor population, and this may lead to an overrepresentation of the poor population in the socioeconomic characteristics analysis.

There were no significant differences between the group with stable couples and the unmarried or widowed group, which differ from the scientific literature that suggests a lower frequen- 
Table 2. Relationship between Clinical Variables and Outcomes in Patients with Penile Cancer Diagnosis in a Tertiary Referral Hospital in Cali, Colombia, 2001-2010.

\begin{tabular}{|c|c|c|c|c|c|c|c|c|c|}
\hline Characteristic & No & Yes & $\mathrm{p}$ & No & Yes & $\mathrm{p}$ & No & Yes & $\mathrm{p}$ \\
\hline \multicolumn{10}{|l|}{ Past medical history } \\
\hline Circumcision & 3 & 0 & 0.74 & 2 & 1 & 0.46 & 0 & 2 & 0.02 \\
\hline Smoking & 15 & 4 & 0.67 & 16 & 3 & 0.57 & 14 & 2 & 0.72 \\
\hline \multicolumn{10}{|l|}{ Form of presentation } \\
\hline Exophytic mass & 23 & 5 & 0.69 & 22 & 6 & 0.50 & 21 & 3 & 0.38 \\
\hline Ulcerative lesion & 13 & 5 & 0.10 & 11 & 7 & 0.01 & 12 & 3 & 0.44 \\
\hline \multicolumn{10}{|l|}{ Treatment } \\
\hline Pharmacological & 0 & 2 & 0.02 & 2 & 0 & 0.64 & 1 & 0 & 0.84 \\
\hline
\end{tabular}

STDs: sexually transmitted diseases.

cy of penile cancer in unmarried men compared with married men ( $15 \%$ and $85 \%$, respectively). ${ }^{17}$ The presence or absence of a steady partner as a risk factor is a subject of controversy. A possible association between cervical cancer and penile cancer has been proposed, since flat penile lesions have been found on $60 \%$ of the men who are partners of women with cervical intraepithelial neoplasia (CIN). ${ }^{21}$ Contrarily, when the presence of premalignant cervical lesions in female partners of men with penile cancer has been studied, the results have not shown a different risk in these women than in the general population. ${ }^{22}$

Ramirez et al. found that the majority of patients with penile cancer were farmers $(49.2 \%)$, similarly to what was found in this study with $37 \%$ of the patients being farmers. ${ }^{17}$ Scientific literature reports that farmers are at higher risk for some neoplasms, such as Hodgkin's lymphoma, multiple myeloma, leukemia, melanomas, and cancers of the lip, stomach, and prostate. However, the association between farmer-related occupation and the development of penile cancer has not yet been established. Literature states that chronic exposure to chemicals commonly encountered in agriculture may predispose farmers to different types of cancers. ${ }^{23-25}$

\section{Past Medical and Social History}

In the present study, only $6.5 \%$ of the patients had phimosis, contrary to higher frequencies between $25 \%-60 \%$ reported previously in patients with penile cancer. ${ }^{5,9}$ In a study by Madsen et al., phimosis was significantly associated with the risk of penile squamous cell carcinoma (odds ratio $[O R]=3.39$ ).$^{26}$ In fact, circumcision, which eliminates the risk of phimosis, has been found to be a protective factor in the development of invasive penile cancer. ${ }^{12,16}$ In this study, there was possibly an underreporting of patients with phimosis due to incomplete data input of the physical examination findings in the patient records, similar to what occurred with schooling and other variables, so awareness in research for health personnel including medical students is required.

Most patients (90.9\%) had never undergone circumcision at diagnosis, which supports the previously reported strong association between undergoing circumcision at birth or during childhood and the lower risk of penile cancer $(O R=0.41) \cdot{ }^{10,16}$ Nevertheless, circumcision does not act as a protective factor in all cases, since it reduces the risk of cancer mainly in patients who have a preexisting condition of phimosis. ${ }^{12}$ It is proposed that phimosis triggers inflammatory processes and the development of chronic injuries by facilitating the chronic irritation of penis mucosa by the smegma components. ${ }^{12,13}$

The present research found that the two patients with history of circumcision had a higher rate of recurrence $(p=0.015)$. This could probably be explained by the fact that in our environment circumcision is usually performed under certain medical conditions (cancer precursor lesions, foreskin tightness, phimosis, or inflammation of the foreskin), which represent all important factors not only for the development but also for the severity of penile cancer. ${ }^{12,13,16}$

History of STDs was reported by $13.3 \%$ of the studied patients, in contrast to previous findings where up to $76 \%$ of patients with penile cancer had a STD history. ${ }^{19}$ The prevalence of HPV infection in patients with penile cancer has been found to be between $15 \%$ and $71 \%$, with most of them having the basaloid or warty specific histological subtypes and the HPV 16 and HPV 18 serotypes. ${ }^{12,28,29}$ However, in this study, no HPV infections were found, probably due to the lack of microbiological studies for HPV in the institution where the study was carried out. With regard to the finding of more frequent history of STDs in younger men, several factors may be involved, including a recall bias in older people and the absence of a clear diagnosis or empirical treatment of possible STDs in older patients.

This research showed that most patients with penile cancer (90.9\%) have a smoking history. The use of tobacco in any form as a risk factor for penile carcinoma has been described in several studies. $5,12,15,19$ Chaux et al., found that $76 \%$ of patients with penile cancer in Paraguay reported past or present consumption of tobacco, mainly in the form of cigarettes, and $55 \%$ of them still held the habit during the time of the study. ${ }^{19}$ smoking seems to have an important role in cases where cigarette smokers have been diagnosed with penile carcinoma, although it may be more important in the advanced stages of progression. ${ }^{12}$

Most patients (78.6\%) reported an evolution time around 2 and 24 months, which is akin with previous reports that identified the delay in care as a very common feature in these patients, where between $25 \%-50 \%$ live with the injury for more than a year before being diagnosed. ${ }^{27}$ 


\section{Clinical Characteristics of Penile Cancer}

It was found that $41.3 \%$ of patients had the penile shaft involved, differing with most of the scientific reports that identified the body of the penis as the least common site of cancer, accounting for less than $5 \%$ of the cases. ${ }^{8,26}$ This could be explained by the level of complexity of the study center and the low social and economic resources of the population, which may cause the patients to carry the disease to more advanced stages. In our study, $27.5 \%$ of patients presented with involvement of more than one region of the penis, similar to a previous study which reported that up to $50 \%$ of the cases affected more than one penile structure. ${ }^{19}$

The study conducted in the same institution as the present study in the previous decade (1990-2000) reported a frequency of $71.3 \%$ for stage T2 diagnosis. ${ }^{17}$ In the present research, $50 \%$ of the cases had a T2 or T3 stage diagnosis. Although this indicates that the majority of patients still present to physicians at an advanced clinical stage, it also shows a decrease of diagnoses at these stages and, possibly, a better care and disease management in the present time. Therefore, follow-up studies that analyze the incidence and presentation of penile cancer in the city are required to evaluate the disease progression and management of patients over the course of the disease.

A higher frequency of metastasis in patients with nodal involvement can be associated with the fact that penile cancer is a malignancy that progresses in a local-regional fashion, involving inguinal and pelvic lymph nodes before developing distant metastases. ${ }^{8,14}$

In our study, patients with a history of STD presented with an ulcerative lesion more frequently than patients with no history of STD, and the association was statistically significant. However, an association between history of STDs and the type of penile cancer lesion has not been previously reported.

\section{Treatment}

The pharmacological management given in higher proportion to patients with metastases $(28.6 \%)$ is consistent with previous reports that showed an increased survival rate in patients with advanced stages that receive chemotherapy. ${ }^{30,31}$ of those patients who underwent radical amputation (20\%) in our study, $55 \%$ also had lymph node dissection and $77 \%$ had an ulcerative type of cancer presentation. This can be correlated with the facts that more advanced stages of the disease present with a greater involvement of lymph nodes and that ulcerative lesions are usually more infiltrative and therefore require a more radical treatment. ${ }^{8,31}$

Many of the results in this study are consistent with those described in the work of Ramirez et al., which was performed in the period 1990-2000 at the Hospital Universitario del VaIle. ${ }^{17}$ Although the number of cases identified over the same study period (10 years) was lower in our study ( 46 vs. 59 ), in both studies the predominant histologic type was squamous cell type carcinoma ( $95.7 \%$ and $100 \%)$, history of smoking was found in most of the patients $(65.5 \%$ and $87 \%$ ) and lack of circumcision was associated with the development of penile carcinoma ( $90.9 \%$ and $80 \%$ ).
One of the limitations of this study is that the study was conducted at a tertiary-level referral institution, which traditionally serves low-income population, so the results cannot be extrapolated to the rest of the Colombian population. However, the results reveal the most important features of these patients, which may facilitate their identification and subsequent management. In this sense, this study presents a description of the cases evaluated without giving the occurrence or incidence of the event in the city of Cali.

Additionally, the nature of the study and the limitations of a retrospective study based on medical records review have to be taken into account. These limitations are mainly due to the loss of data, lack of information on medical records and failure to investigate risk factors and variables of interest. Certain variables that could have increased the significance of the association hypothesis were not included. In the case of smoking, the starting age or the Index of Packs per Year (IPA) was not taken into account. Regarding the sociodemographic variables, addressing the patient's salary or socioeconomic status would be useful to establish a stronger association between poverty and penile cancer. Knowing the total number of sexual partners or the age of the first intercourse would provide information on further exposure to behaviors that increase the risk of STDs and therefore penile cancer. There was no information regarding the hygiene habits of the patient, which has been widely associated with the development of penile cancer. ${ }^{19}$

Most of the results found in this study agree with those previously reported in the scientific literature; however, many of the limitations encountered during this project were related to the poor handling of the medical records and with it the great amount of valuable data lost. Therefore, it is necessary to remind the medical staff responsible for filling out the medical records about the importance of recoding minimally necessary data, including sociodemographic characteristics. In this way, more robust studies and the establishment of significant risk factors can be made.

As a conclusion, most of the patients with penile cancer found at this referral center had old age, history of tobacco use and lack of circumcision. The patients who presented in more advanced stages of the disease with lymph node metastasis had to undergo more radical procedures and presented a greater rate of recurrence compared with those with no lymph node involvement. Further research to establish associated factors and test the proposed hypothesis resulted from this study are needed to enable a better understanding of penile cancer. 


\section{References}

1. Curado MP, Edwards B, Shin HR, Storm H, Ferlay J, Heanue M, et al. Cancer Incidence in Five Continents. France: International Agency for Research on Cancer (IARC). World Health Organization; 2007p.

2. Jemal A, Siegel R, Ward E, Murray T, Xu J, Thun MJ. Cancer statistics, 2007. CA Cancer J Clin. 2007 Jan-Feb;57(1):43-66.

3. Parkin DM, Ferlay J, Curado MP, Bray F, Edwards B, Shin HR, et al. Fifty years of cancer incidence: $\mathrm{Cl}_{5}$ I-IX. Int J Cancer. 2010 Dec 15;127(12):2918-27. 4. Velazquez EF, Cubilla AL. Penile squamous cell carcinoma: anatomic, pathologic and viral studies in Paraguay (1993-2007). Anal Quant Cytol Histol. 2007 Aug;29(4):185-98.

5. Favorito LA, Nardi AC, Ronalsa M, Zequi SC, Sampaio FJ, Glina S. Epidemiologic study on penile cancer in Brazil. Int Braz J Urol. 2008 Sep-0ct;34(5):587-93. 6. Cubilla AL. The role of pathologic prognostic factors in squamous cell carcinoma of the penis. World J Urol. 2009 Apr;27(2):169-77.

7. Cubilla AL, Velazquez EF, Young RH. Epithelial lesions associated with invasive penile squamous cell carcinoma: a pathologic study of 288 cases. Int J Surg Pathol. 2004 0ct;12(4):351-64.

8. Kayes 0 , Ahmed HU, Arya M, Minhas S. Molecular and genetic pathways in penile cancer. Lancet Oncol. 2007 May;8(5):420-9.

9. Gross G, Pfister H. Role of human papillomavirus in penile cancer, penile intraepithelial squamous cell neoplasias and in genital warts. Med Microbiol Immunol. 2004 Feb;193(1):35-44.

10. van Geel AN, den Bakker MA, Kirkels W, Horenblas S, Kroon BB, de Wilt JH, et al. Prognosis of primary mucosal penile melanoma: a series of 19 Dutch patients and 47 patients from the literature. Urology. 2007 Jul;70(1):143-7.

11. Fetsch JF, Davis Jr CJ, Miettinen M, Sesterhenn IA. Leiomyosarcoma of the penis: a clinicopathologic study of 14 cases with review of the literature and discussion of the differential diagnosis. Am J Surg Pathol. 2004 Jan;28(1):115-25.

12. Daling JR, Madeleine MM, Johnson LG, Schwartz SM, Shera KA, Wurscher MA, et al. Penile cancer: importance of circumcision, human papillomavirus and smoking in in situ and invasive disease. Int J Cancer. 2005 Sep 10;116(4):606-16.

13. Calmon MF, Tasso Mota M, Vassallo J, Rahal P. Penile carcinoma: risk factors and molecular alterations. ScientificWorldjournal. 2011 Feb 3;11:269-82. 14. Pow-Sang MR, Ferreira U, Pow-Sang JM, Nardi AC, Destefano V. Epidemiology and natural history of penile cancer. Urology. 2010 Aug;76(2 Suppl 1):S2-6.

15. Madsen BS, van den Brule AJ, Jensen HL, Wohlfahrt J, Frisch M. Risk factors for squamous cell carcinoma of the penis-population-based case-control study in Denmark. Cancer Epidemiol Biomarkers Prev. 2008 Oct;17(10):2683-91.

16. Larke NL, Thomas SL, dos Santos Silva I, Weiss HA. Male circumcision and penile cancer: a systematic review and meta-analysis. Cancer Causes Control. 2011 Aug;22(8):1097-110.

17. Ramírez G, Bermúdez A]. [Penile Carcinoma in the Universitary Hospital del Valle]. Urol Colomb. 2004 Aug;13(2):47-50.
18. von Elm E, Altman DG, Egger M, Pocock SJ, Gotzsche PC, Vandenbroucke JP. The Strengthening the Reporting of Observational Studies in Epidemiology (STROBE) statement: guidelines for reporting observational studies. PLOS medicine. 2007 Oct 16;4(10):e296.

19. Chaux A, Netto GJ, Rodríguez IM, Barreto JE, Oertell J, Ocampos S, et al. Epidemiologic profile, sexual history, pathologic features, and human papillomavirus status of 103 patients with penile carcinoma. World J Urol. 2013 Aug;31(4):861-7.

20. Hernandez BY, Barnholtz-Sloan J, German RR, Giuliano A, Goodman MT, King JB, et al. Burden of invasive squamous cell carcinoma of the penis in the United States, 1998-2003. Cancer. 2008 Nov 15;113(10 Suppl):2883-91.

21. Bleeker MC, Hogewoning CJ, Voorhorst FJ, van den Brule AJ, Berkhof J, Hesselink AT, et al. HPV-associated flat penile lesions in men of a non-STD hospital population: less frequent and smaller in size than in male sexual partners of women with CIN. Int J Cancer. 2005 Jan 1;113(1):36-41.

22. de Bruijn RE, Heideman DA, Kenter GG, van Beurden M, van Tinteren H, Horenblas S. Patients with penile cancer and the risk of (pre) malignant cervical lesions in female partners: a retrospective cohort analysis. BJU Int. 2013 Nov;112(7):905-8.

23. Blair A, Zahm SH, Pearce NE, Heineman EF, Fraumeni JF Jr. Clues to cancer etiology from studies of farmers. Scand J Work Environ Health. 1992 Aug; 18(4):209-15.

24. Dich J, Zahm SH, Hanberg A, Adami HO. Pesticides and cancer. Cancer Causes Control. 1997 May;8(3):420-43.

25. Blair A, Malker H, Cantor KP, Burmeister L, Wiklund K. Cancer among farmers. A review. Scand J Work Environ Health. 1985 Dec;11(6):397-407.

26. Barnholtz-Sloan JS, Maldonado JL, Pow-Sang J, Guiliano AR. Incidence trends in primary malignant penile cancer. Urologic Oncology: Seminars and Original Investigations; 2007: Elsevier; 2007. p. 361-7.

27. Pow-Sang MR, Benavente V, Pow-Sang JE, Morante C, Meza L, Baker M, et al. Cancer of the penis. Cancer control. 2002 Jul-Aug;9(4):305-14.

28. D’Hauwers K, Depuydt C, Bogers J, Noel J, Delvenne P, Marbaix E, et al. Human papillomavirus, lichen sclerosus and penile cancer: a study in Belgium. Vaccine. 2012;30(46):6573-7.

29. Backes DM, Kurman RJ, Pimenta JM, Smith JS. Systematic review of human papillomavirus prevalence in invasive penile cancer. Cancer Causes it Control. 2009;20(4):449-57.

30. Pettaway CA, Pagliaro L, Theodore C, Haas C. Treatment of visceral, unresectable, or bulky/unresectable regional metastases of penile cancer. Urology. 2010;76(2):S58-S65.

31. Guimarães CC, Rocha RM, Zequi SC, Cunha IW, Soares FA. Penile cancer: epidemiology and treatment. Current oncology reports. 2011;13(3):231-9.

32. Block SL, Nolan T, Sattler C, Barr E, Giacoletti KE, Marchant CD, et al. Comparison of the immunogenicity and reactogenicity of a prophylactic quadrivalent human papillomavirus (types $6,11,16$, and 18) L1 virus-like particle vaccine in male and female adolescents and young adult women. Pediatrics. 2006;118(5):2135-45.

\section{Acknowledgments}

To Ivan Escobar for his critical revision to the manuscript.

Conflict of Interest Statement a Funding

The Authors have no funding, financial relationships or conflicts of interest to disclose.

\section{Author Contributions}

Conception and design the work/idea: LMR, MMH, ALRJ, AJBP, FJBE. Collect data/obtaining results: LMR, MMH, ALRJ. Analysis and interpretation of data: LMR, MMH, ALRJ, FJBE. Write the manuscript: LMR, MMH, ALRJ, FJBE. Critical revision of the manuscript: LMR, MMH, ALRJ, AJBP, FJBE. Approval of the final version: LMR, MMH, ALRJ, AJBP, FJBE. Contribution of patients or study material: AJBP. Statistical advice: FJBE. Administrative or technical advice: AJBP, FJBE.

Cite as:

Rengifo LM, Herrera M del M, Rincon-Jimenez AL, Bermudez-Pupo AJ, Bonilla-Escobar FJ. Penile Cancer in Cali, Colombia: 10 Years of Casuistry in a Tertiary Referral Center of a Middle-Income Country. Int J Med Students. 2014 Jul-0ct;2(3):109-14. 